\title{
Estudo imuno-histoquímico de componentes da membrana basal em cistos odontogênicos
}

\section{Immunohistochemical study of components of the basement membrane in odontogenic cysts}

\author{
Marcilio Dias Chaves de Oliveira* \\ Lélia Batista de Souza** \\ Leão Pereira Pinto** \\ Roseana de Almeida Freitas**
}

\begin{abstract}
RESUMO: Com o objetivo de observar o padrão de distribuição de proteínas da membrana basal de cistos odontogêni$\cos$, foi realizado um estudo imuno-histoquímico em dez espécimes de cisto radicular, dez cistos dentígeros e dez ceratocistos odontogênicos, por meio do uso de anticorpos antilaminina e anticolágeno IV. Os resultados mostraram uma marcação linear fraca e descontínua nos ceratocistos, tanto da laminina, quanto do colágeno IV, enquanto nos cistos radiculares, esta marcação foi mais intensa e contínua. Nos cistos dentígeros, foi observado um padrão intermediário, tendendo mais ao observado nos ceratocistos. Nossos resultados sugerem que, através da fraca expressão das proteínas de membrana basal observada nos ceratocistos odontogênicos, possiveis modificações nas relações interativas entre o epitélio e o tecido conjuntivo adjacente devem acontecer, o que poderia contribuir, em parte, para o padrão de crescimento mais agressivo exibido por este tipo de cisto.
\end{abstract}

UNITERMOS: Cistos odontogênicos; Laminina; Colágeno; Membrana basal.

\begin{abstract}
The pattern of distribution and expression of laminin and type IV collagen was studied in ten radicular cysts, ten dentigerous cysts and ten odontogenic keratocysts, by means of the streptavidin-biotin method. The purpose of this study was to investigate changes in the distribution of components of the basement membrane in an attempt to contribute to the understanding of the differences, as to evolution and clinical behavior, between these cysts. The results revealed a weak and discontinuous linear staining, in odontogenic keratocysts, for both laminin and type IV collagen, while, in radicular cysts, staining was more intense and continuous. In dentigerous cysts, an intermediary pattern was observed, which was more similar to that observed in keratocysts. Our results suggest that, in view of the weak expression of proteins of the basement membrane observed in odontogenic keratocysts, modifications must take place in the interaction between the epithelium and the adjacent connective tissue, which could, in part, contribute to the pattern of more rapid growth exhibited by these cysts.

UNITERMS: Odontogenic cysts; Laminin; Collagen; Basement membrane.
\end{abstract}

\section{INTRODUÇÃO}

Apesar da origem em comum a partir de remanescentes epiteliais da odontogênese, os cistos radiculares, dentígeros e ceratocistos apresentam evolução e comportamento clínico diferentes ${ }^{15}$. Em decorrência dessas diferenças é que vários autores pesquisaram e continuam pesquisando possiveis diferenças entre o potencial de crescimento desses cistos, por meio das mais variadas metodologias. Entretanto, a maior parte desses pesquisadores direcionou seus estudos para as características proliferativas dos revestimentos epiteliais dos cistos estudados. Freitas; Serafim ${ }^{8}$ (1998) sugerem que, para um melhor entendimento do comporta- mento biológico exibido pelo ceratocisto odontogênico e cisto dentígero, faz-se necessário dirigir a atenção de novos estudos para constituintes da matriz extracelular a fim de se obterem dados indicadores a respeito da interação entre esta matriz e o epitélio de revestimento cístico.

A membrana basal é uma delgada lâmina de matriz extracelular que reveste células nervosas, adiposas e musculares, além de separar células epiteliais do tecido conjuntivo subjacente ${ }^{7}$. Dentre as suas várias funções, ela participa no processo de reparo e orientação para a proliferação celular ${ }^{1}$, induz a diferenciação celular e atua como estradas específicas para a migração celular ${ }^{2}$, serve como

*Professor Doutor da Disciplina de Endodontia; **Professores Doutores da Disciplina de Patologia Oral - Departamento de Odontologia da Universidade Federal do Rio Grande do Norte. 
OLIVEIRA MDC de, SOUZA LB de, PINTO LP, FREITAS R de A. Estudo imuno-histoquímico de componentes da membrana basal em cistos odontogênicos. Pesqui Odontol Bras 2002;16(2):157-162.

barreira estrutural ao processo de invasão e metástase das células malignas ${ }^{14}$, mantém a polaridade e diferenciação dos estratos celulares da pele e controla a invasão por células tumorais ${ }^{9}$.

A membrana basal é composta por diversas moléculas, destacando-se dentre elas a laminina e o colágeno IV, que estão presentes em todas elas ${ }^{7,9}$.

A laminina é uma glicoproteína de alto peso molecular, formada por três cadeias muito longas de polipeptídeos organizadas em forma de uma cruz assimétrica e mantidas unidas através de pontes dissulfeto e sintetizada por células epidérmicas ${ }^{2,9}$. Ela atua como mediador da adesão de grande número de diferentes células ao substrato, liga-se ao colágeno IV, ao sulfato de heparana, à entactina $\mathrm{e}$ a outros receptores protéicos localizados nas superficies das células ${ }^{2,9}$. A laminina regula uma variedade de fenômenos biológicos incluindo fixação, crescimento, morfologia e migração celular. Certos tipos de células normais e neoplásicas contêm locais de ligação de alta afinidade pela laminina ${ }^{14}$.

O colágeno IV é uma proteína de alto peso molecular, formado por duas cadeias polipeptídicas, alfa 1 e alfa 2 unidas numa só molécula tri-helicoidal que se dispõe em forma de rede ${ }^{2,9}$. Alberts et al. ${ }^{2}$ (1997) e Liotta $^{14}$ (1984) afirmam que o colágeno IV é uma proteína fibrosa que forma a parte principal da membrana basal sobre a qual os outros componentes da matriz são montados.

Vários trabalhos foram realizados sobre a expressão dos componentes da membrana basal (laminina e colágeno IV) com objetivo de detectar a distribuição e alguma diferença nesses componentes em lesões malignas e proliferativas em diversas partes do organismo. Pouquíssimos estudos avaliaram características destes componentes em cistos odontogênicos, dentre estes o de Silva ${ }^{17}$ (2000), que comparou os cistos odontogênicos ortoceratinizados aos ceratocistos odontogênicos.

Nosso trabalho objetivou analisar o padrão de distribuição da laminina e do colágeno IV em cistos odontogênicos, visando a obtenção de dados que possam vir a contribuir para um melhor entendimento do comportamento biológico dessas lesões.

\section{MATERIAL E MÉTODOS}

Dez espécimes de cistos radiculares, dez cistos dentígeros e dez ceratocistos odontogênicos pertencentes aos arquivos da Disciplina de Patologia Oral do Curso de Odontologia da Universidade Federal do Rio Grande do Norte foram utilizados neste estu- do. Para a seleção dessa amostra, analisaram-se dados radiográficos, cirúrgicos e histopatológicos, particularmente no caso dos cistos dentígeros, para os quais foi necessária a sua confirmação, por meio do diagnóstico cirúrgico. Para a análise imuno-histoquímica, foram obtidos cortes de $3 \mu \mathrm{m}$ de espessura a partir de espécimes teciduais fixados em formol a $10 \%$ e incluídos em parafina. Os cortes obtidos foram corados pelo método da estreptavidina-biotina, tendo como soros primários o LAM-89 (Sigma Chemical Co., EUA) antilaminina e o CIV22 (DAKO A/S, Dinamarca) anticolágeno IV. A recuperação antigênica foi realizada com pepsina a $1 \%$, a $37^{\circ} \mathrm{C}$ durante 60 minutos e, posteriormente, os cortes foram incubados em solução cromógena de diaminobenzidina a 0,03\%.

Após a coloração, cada caso foi, então, analisado ao microscópio de luz e as características do padrão da expressão (localização, espessura, continuidade e intensidade) de cada constituinte da membrana basal estudado foram anotadas em fichas individuais. Procedeu-se, então, a uma análise comparativa entre as características inerentes a cada tipo cístico estudado.

\section{RESULTADOS}

Todos os espécimes empregados neste estudo exibiram imunorreatividades aos anticorpos utilizados, tendo sido usada como controle interno positivo a imunomarcação em membrana basal dos vasos sangüineos.

A laminina apresentou um padrão de marcação linear e descontínuo ao longo da membrana basal de espessura delgada em todos os cistos examinados, com exceção de três casos de cistos radiculares, onde a marcação apresentou-se contínua. A

TABELA 1 - Padrão de expressão da laminina nos cistos radiculares, dentígeros e ceratocistos estudados. Natal RN, 2000.

\begin{tabular}{l|c|c|c|c|c|c|c}
\hline \hline \multirow{2}{*}{ Cistos } & \multicolumn{2}{|c|}{ Espessura } & \multicolumn{2}{|c|}{ Continuidade } & \multicolumn{3}{|c}{ Intensidade } \\
\cline { 2 - 8 } & $\mathrm{D}$ & $\mathrm{E}$ & $\mathrm{C}$ & $\mathrm{Ds}$ & $\mathrm{Fr}$ & $\mathrm{M}$ & $\mathrm{I}$ \\
\hline $\begin{array}{l}\text { Cisto ra- } \\
\text { dicular }\end{array}$ & 10 & - & 3 & 7 & - & 6 & 4 \\
\hline $\begin{array}{l}\text { Cisto } \\
\text { dentígero }\end{array}$ & 10 & - & - & 10 & 9 & 1 & - \\
\hline $\begin{array}{l}\text { Cerato- } \\
\text { cisto }\end{array}$ & 10 & - & - & 10 & 9 & 1 & - \\
\hline \hline
\end{tabular}

$\mathrm{D}=$ delgado, $\mathrm{E}$ = espesso, $\mathrm{C}=$ contínuo, $\mathrm{Ds}=$ descontínuo, $\mathrm{Fr}=$ fraco, $\mathrm{M}=$ moderado, $\mathrm{I}=$ intenso. 
OLIVEIRA MDC de, SOUZA LB de, PINTO LP, FREITAS R de A. Estudo imuno-histoquímico de componentes da membrana basal em cistos odontogênicos. Pesqui Odontol Bras 2002;16(2):157-162.

intensidade da imunomarcação apresentou-se predominantemente fraca nos cistos dentígeros e ceratocistos. Já os cistos radiculares exibiram, em seis casos, imunorreatividade moderada e nos outros quatro, intensa (Tabela 1 e Figuras 1, 2 e 3).

A imunorreatividade dos cistos estudados pelo anticorpo anticolágeno IV mostrou regularidade quanto à espessura da marcação linear em zona subepitelial, tendo se apresentado em todos, como uma linha delgada, com exceção de dois cistos dentígeros que se apresentaram com algumas áreas mais espessas. Já em relação à continuidade da marcação linear, os cistos radiculares apresentaram continuidade em cinco espécimes, os dentígeros em quatro e nenhum dos ceratocistos exibiu esta continuidade. A intensidade da imunocoloração nos cistos radiculares e nos cistos dentígeros foi mais intensa que nos ceratocistos, uma vez que seis dos radiculares e cinco dos dentígeros exibiram imunorreação entre moderada e intensa, contra apenas um caso dos ceratocistos, uma vez que nos outros nove casos, a marcação foi predominantemente fraca (Tabela 2 e Figuras 4, 5 e 6).

\section{DISCUSSÃO}

Muitos trabalhos comparativos foram realizados sobre as características referentes à diferenciação e ao crescimento dos revestimentos epiteliais dos cistos radiculares, dentígeros e ceratocistos odontogênicos e, em quase todos eles, foram demonstradas diferenças no potencial proliferativo dos revestimentos epiteliais desses cistos, sendo constatada maior capacidade proliferativa nos ceratocistos, seguido dos cistos dentígeros e, por fim, dos cistos radiculares, o que corrobora seus comportamentos biológicos.

Os processos que levam essas células a proliferarem em ritmos diferentes e a apresentarem características clínicas diversas é, ainda, motivo de estudos e discussões. Sabe-se que a matriz extracelular desempenha papel ativo e complexo na regulação do comportamento das células com as quais faz contato ${ }^{2}$. É observado, na literatura, um grande número de autores que estudaram, através da identificação imuno-histoquímica dos componentes da membrana basal, as diferenças apresentadas por esses componentes em diversas alterações teciduais hiperplásicas, displásicas e neoplásicas e, de posse de seus achados, tentaram correlacioná-los com os aspectos histológicos e

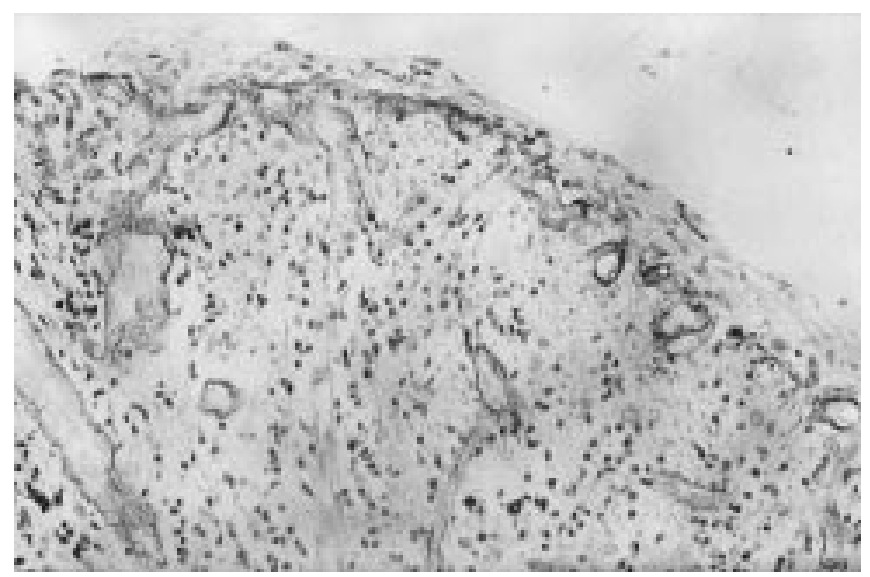

FIGURA 1 - Expressão linear com pequenos focos de descontinuidade da laminina em membrana basal da interface epitélio/mesênquima em cisto radicular (estreptavidina-biotina, $200 \mathrm{X}$ ).

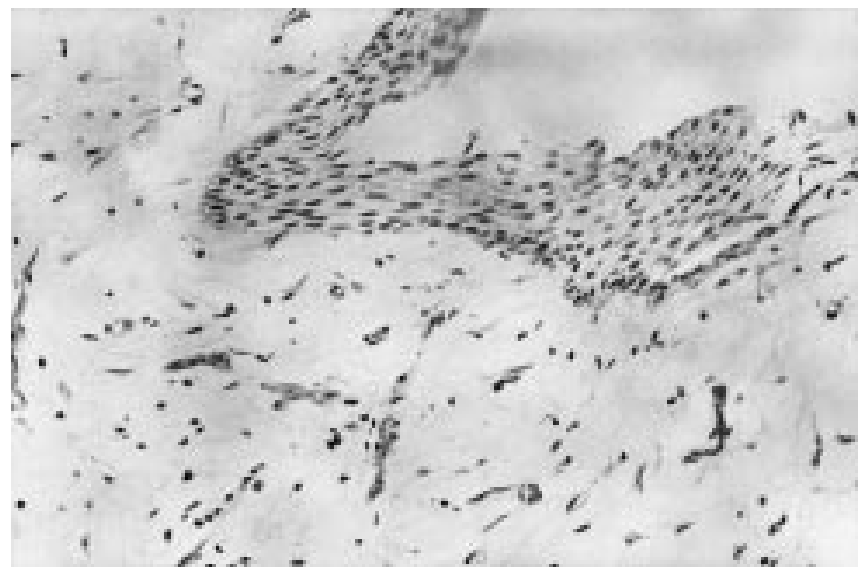

FIGURA 2 - Fraca expressão da laminina em membrana basal subepitelial em cisto dentígero (estreptavidinabiotina, $200 \mathrm{X})$.

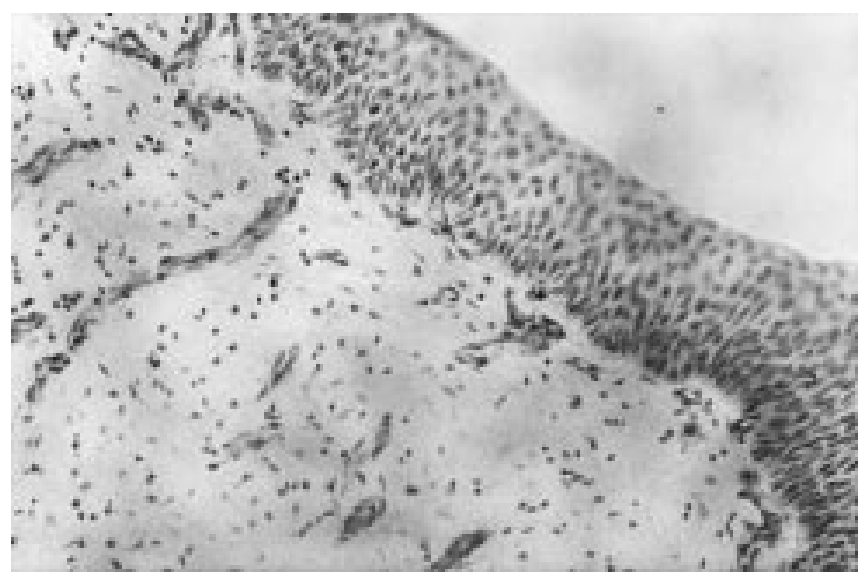

FIGURA 3 - Extensa área de ausência de marcação da laminina em membrana basal na interface epitélio/mesênquima em ceratocisto odontogênico (estreptavidina-biotina, $200 \mathrm{X}$ ). 
OLIVEIRA MDC de, SOUZA LB de, PINTO LP, FREITAS R de A. Estudo imuno-histoquímico de componentes da membrana basal em cistos odontogênicos. Pesqui Odontol Bras 2002;16(2):157-162.

TABELA 2 - Padrão de expressão do colágeno IV nos cistos radiculares, dentígeros e ceratocistos estudados. Natal - RN, 2000.

\begin{tabular}{l|r|c|c|c|c|c|c|c}
\hline \hline \multirow{2}{*}{ Cistos } & \multicolumn{2}{|c|}{ Espessura } & \multicolumn{3}{|c|}{ Continuidade } & \multicolumn{3}{|c}{ Intensidade } \\
\cline { 2 - 10 } & $\mathrm{D}$ & $\mathrm{E}$ & $\mathrm{D} / \mathrm{E}$ & $\mathrm{C}$ & $\mathrm{Ds}$ & $\mathrm{Fr}$ & $\mathrm{M}$ & $\mathrm{I}$ \\
\hline Cisto radicular & 10 & - & - & 5 & 5 & 4 & 5 & 1 \\
\hline Cisto dentígero & 8 & - & 2 & 4 & 6 & 5 & 3 & 2 \\
\hline Ceratocisto & 10 & - & - & - & 10 & 9 & 1 & - \\
\hline \hline
\end{tabular}

$\mathrm{D}=$ delgado, $\mathrm{E}=$ espesso, $\mathrm{D} / \mathrm{E}=$ misto de áreas delgadas e áreas espessas, $\mathrm{Fr}=$ fraco, $\mathrm{M}=$ moderado, $\mathrm{I}=$ intenso, $\mathrm{C}=$ contínuo, $\mathrm{Ds}=$ descontínuo.

comportamentos clínicos dessas entidades. Em nosso trabalho, foi realizado um estudo similar com cistos radiculares, dentígeros e ceratocistos odontogênicos.

De acordo com Alberts et al. ${ }^{2}$ (1997) e Lee, Streu$\mathrm{li}^{13}$ (1999), a interação molecular entre os componentes da matriz extracelular e os receptores de superficie celular regula algumas funções celulares, incluindo proliferação, apoptose, diferenciação e migração celular. Autores como Abrahamson ${ }^{1}$ (1986), González et al. ${ }^{9}$ (1994) e Liotta $^{14}$ (1984) imputam como função da membrana basal e em especial da laminina, dentre outras, a de fixação e crescimento das células com as quais está em contato. Abrahamson $^{1}$ (1986) cita, ainda, que a membrana basal serve de orientação para a proliferação celular.

Os dados observados em nosso trabalho nos três cistos radiculares que apresentaram expressão da laminina em membrana basal contínua e intensamente marcada, comparam-se ao observado em tecidos epiteliais normais e corroboram os achados de vários autores, que confirmaram serem esses cistos os que evoluem mais lentamente dentre os cistos estudados. O infiltrado inflamatório nesses três cistos era intenso, mas se encontrava distante do epitélio, diferente dos sete que exibiram a marcação descontínua e moderada, cujo infiltrado inflamatório encontrava-se variando de moderado a intenso e localizado em áreas da cápsula em intima relação com o epitélio. A descontinuidade na marcação nesses cistos pode ser justificada pela presença do infiltrado inflamatório justa-epitelial pois, conforme afirma Abrahamson ${ }^{1}$ (1986), alterações na integridade da membrana basal podem ser decorrentes da ação de enzimas proteolíticas elaboradas por células inflamatórias.

Todos os cistos dentígeros e os ceratocistos apresentaram uma marcação linear delgada, des-

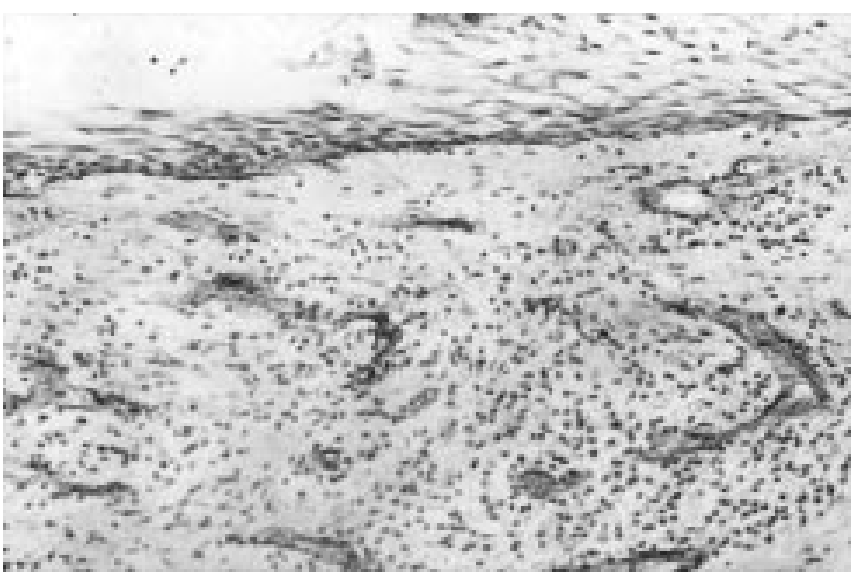

FIGURA 4 - Forte expressão linear e contínua do colágeno IV em membrana basal subepitelial em cisto radicular (estreptavidina-biotina, $200 \mathrm{X}$ ).

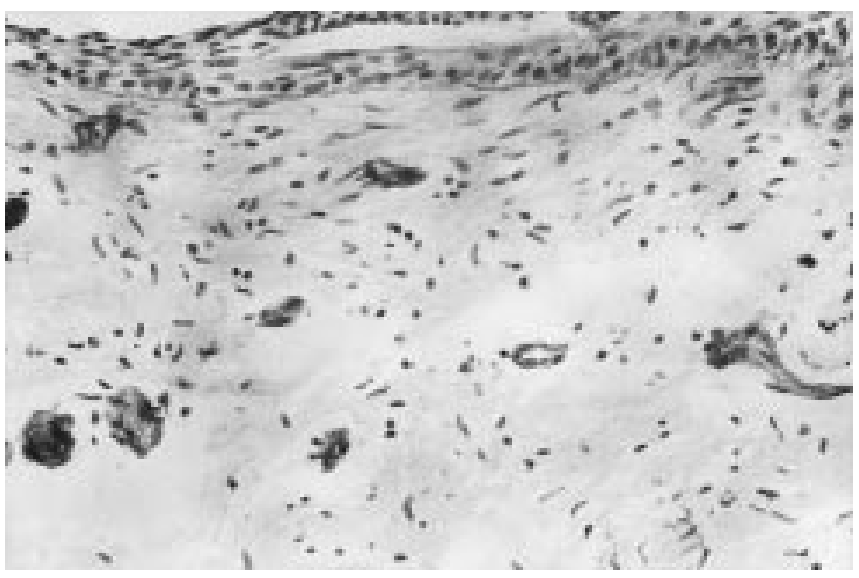

FIGURA 5 - Moderada expressão linear com focos de descontinuidade do colágeno IV em membrana basal subepitelial em cisto dentígero (estreptavidina-biotina, $200 \mathrm{X})$.

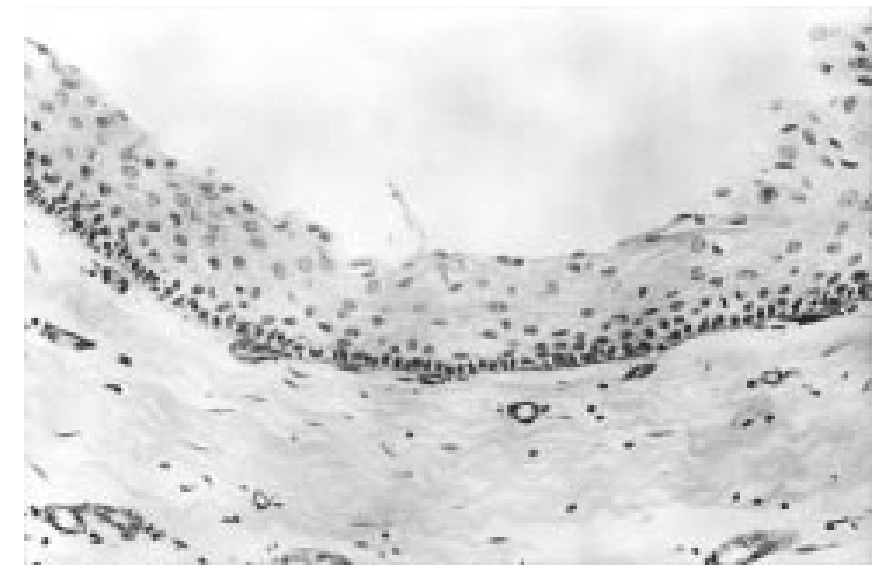

FIGURA 6 - Expressão linear e descontínua do colágeno IV em membrana basal da interface epitélio/mesênquima em ceratocisto odontogênico (estreptavidina-biotina, $200 \mathrm{X})$. 
OLIVEIRA MDC de, SOUZA LB de, PINTO LP, FREITAS R de A. Estudo imuno-histoquímico de componentes da membrana basal em cistos odontogênicos. Pesqui Odontol Bras 2002;16(2):157-162.

contínua e fraca. Nesses cistos, não poderíamos correlacionar essa descontinuidade com o infiltrado inflamatório, uma vez que a quantidade deste infiltrado nesses cistos variou de escassa a ausente e sempre em áreas mais afastadas do epitélio. Falhas no mecanismo de controle da degradação dos componentes da membrana ou falha na sintese destes componentes, como relatam alguns autores $^{4,5}$ devem ter ocorrido, o que justificaria esta marcante descontinuidade observada.

A falha na estrutura da laminina em ceratocistos pode nos levar a especular sobre uma possivel influência desse fato sobre a capacidade de proliferação epitelial desses cistos, assim como sobre uma outra característica peculiar aos ceratocistos, que é a de o epitélio tender a se desgarrar do conjuntivo. Alguns autores imputam a esse desprendimento a capacidade recidivante dos ceratocistos após sua remoção cirúrgica ${ }^{4,5}$.

Bellinghieri et al. ${ }^{3}$ (1997), estudando espécimes de rins obtidos de pacientes afetados pela doença renal policística autossômica dominante, demonstraram a importância da matriz extracelular frente à formação de cistos e concluíram que a perda da laminina na membrana basal nestes cistos renais pode induzir à formação e crescimento dos mesmos, o que reforça o que descrevemos acima.

Em tecido normal e doenças benignas, alguns autores descrevem a marcação do colágeno IV como uma linha contínua, espessa e fortemente marcada $^{12,18}$. Em nosso trabalho, pudemos observar que os cistos radiculares mostraram, no geral, a expressão do colágeno IV de forma mais contínua e intensa, o que se aproxima desse padrão de marcação descrito para tecidos normais. Os ceratocistos, por sua vez, exibiram uma marcação linear delgada marcadamente descontínua e fraca, o que poderia exercer alguma influência sobre o potencial proliferativo deste cisto, uma vez que a perda da integridade da membrana basal pode favorecer alterações nas relações de interação epitélio/mesênquima.

A descontinuidade e fraca marcação observadas no padrão de expressão do colágeno IV característico dos ceratocistos estudados tornam-se ainda mais importantes, quando verificamos que o infiltrado inflamatório parece não exercer influência sobre esta expressão, conforme citado anteriormente. Já nos cistos radiculares e nos dentígeros, quando o padrão de descontinuidade estava presente, geralmente associava-se a intima relação com a inflamação. Estes achados corroboram mais uma vez os de Abrahamson ${ }^{1}$ (1986).

Provavelmente, estas falhas da membrana basal, evidenciadas em ceratocistos, favoreçam o constante destacamento do epitélio em relação ao tecido conjuntivo, freqüentemente relatado na literatura e também por nós evidenciados nos dez casos analisados, além de poder exercer influência no sentido de alterar as relações interativas entre as células do revestimento epitelial com constituintes da matriz extracelular, relações estas que dependem da integridade da membrana basal para se processarem de forma satisfatória. Com base nas funções da membrana basal conhecidas e citadas por vários estudiosos do assunto ${ }^{1,2,9,14}$, destacando-se sua atuação no controle da proliferação, diferenciação e migração celulares, fica claro o quanto estes processos podem encontrar-se alterados nos ceratocistos, o que viria a corroborar os achados freqüentemente intrigantes do quadro evolutivo mais agressivo deste cisto em relação aos outros analisados. Estudos de cinética celular realizados em cistos odontogênicos imputam ao revestimento epitelial do ceratocisto o maior potencial proliferativo verificado ${ }^{11,16}$.

Ao nosso ver, estas falhas na integridade da membrana basal, verificadas nos ceratocistos por nós estudados, podem influenciar, sobremaneira, nas sinalizações entre as células epiteliais e constituintes da matriz extracelular. Como não sabemos responder ainda à dúvida levantada por Browne $^{6}$, em 1975, de que se o defeito primário desencadeante para a formação do ceratocisto está nas células epiteliais ou no mesênquima adjacente, podemos, pelo menos, sugerir a partir dos nossos achados que a sinalização entre o epitélio e a cápsula cística está modificada, o que poderia contribuir para o desenvolvimento, a capacidade expansiva e/ou o comportamento biológico mais agressivo verificado nesta lesão.

Achados semelhantes aos nossos em relação à imunomarcação da laminina e do colágeno IV nos ceratocistos odontogênicos foram verificados por Silva $^{17}$ (2000) em estudo comparativo aos cistos odontogênicos ortoceratinizados. O autor sugere que, possivelmente, a contínua expansão verificada nos ceratocistos poderia influenciar no desaparecimento focal destas proteínas na membrana basal dos forros epiteliais, sendo, entretanto, ao mesmo tempo, indispensáveis para a manutenção da morfologia e integridade dos mesmos. 
OLIVEIRA MDC de, SOUZA LB de, PINTO LP, FREITAS R de A. Estudo imuno-histoquímico de componentes da membrana basal em cistos odontogênicos. Pesqui Odontol Bras 2002;16(2):157-162.

Acreditamos que nossos achados, somados àqueles a respeito do potencial proliferativo dos revestimentos epiteliais císticos, vêm contribuir para o melhor entendimento das diferenças verificadas nos comportamentos biológicos dos cistos radiculares, dentígeros e ceratocistos. Neste último tipo cístico, a fraca expressão da laminina e do colágeno IV na membrana basal do forro epitelial, propiciaria modificações nas sinalizações entre o epitélio e a cápsula fibrosa deste cisto, podendo contribuir para um padrão hiperproliferativo do epitélio, o qual vem sendo constantemente detectado por meio das mais variadas metodologias.

Frente a estes fatos, parece-nos possivel sugerir, a exemplo do que já foi proposto por Hirshberg et al. ${ }^{10}$ (1999), que a cápsula fibrosa do ceratocisto odontogênico não representa apenas um suporte estrutural para a lesão, mas sim, um fator, em parte, responsável e determinante do comportamento deste cisto, que vem sendo considerado por um representativo número de autores, como um neoplasma cístico. A possibilidade de o ceratocisto odontogênico possuir

\section{REFERÊNCIAS}

1. Abrahamson DR. Recent studies on the structure and pathology of basement membranes. J Pathol 1986;149:257-78.

2. Alberts B, Bray D, Lewis J, et al. Biologia molecular da célula. 3. ed. Porto Alegre : Artes Médicas, 1997. Cap. 19: Junções celulares, adesão celular e a matriz extracelular, p. 949-1009.

3. Bellinghieri G, Magaudda L, Santoro D, et al. Extracellular matrix abnormality may be responsible for cysts development. Contrib Nephrol 1997;122:38-44.

4. Brannon RB. The odontogenic keratocyst. A clinicopathologic study of 312 cases. Part II. Histologic features. Oral Surg Oral Med Oral Pathol Oral Radiol Endod 1977;43:233-55.

5. Browne RM. The odontogenic keratocyst: histological features and their correlation with clinical behavior. Br Dent $\mathrm{J}$ 1971;131:249-59.

6. Browne RM. The pathogenesis of odontogenic cysts: a review. J Oral Pathol 1975;4:31-46.

7. Della Colleta R, Jorge Junior J, Lopes MA, et al. Expressão de laminina no germe dental do primeiro molar de ratos em desenvolvimento. RPG 1997;4:87-92.

8. Freitas RA, Serafim FMA. Regiões organizadoras nucleolares (AgNORs) em cistos dentígeros e ceratocisto odontogênico. RPG 1998;5:202-5.

9. González S, Pérez-Cotapos ML, Bolte C, et al. Avances en la estructura y función de la membrana basal. Dermatol Chile 1994;10:181-4.

10. Hirshberg A, Sherman S, Buchner A, et al. Collagen fibres in the wall of odontogenic keratcysts: a study with picrosirius red polarizing microscopy. J Oral Pathol Med 1999;28:410-2. um comportamento neoplásico, há muito é discutida, em virtude de seu quadro evolutivo freqüentemente agressivo em relação aos outros cistos odontogênicos, entretanto, dados conclusivos sobre estas dúvidas ainda necessitam de maiores explorações.

\section{CONCLUSÕES}

A laminina e o colágeno IV apresentaram um padrão de marcação linear em membrana basal do forro epitelial mais contínuo e intenso nos cistos radiculares, enquanto nos ceratocistos odontogênicos, foi descontínuo e fraco. Os cistos dentígeros apresentaram um padrão intermediário entre os citados anteriormente.

A fraca expressão da laminina e do colágeno IV na membrana basal dos ceratocistos odontogênicos sugere que possiveis modificações nas relações interativas entre o epitélio e o tecido conjuntivo adjacente devem ocorrer, o que poderia contribuir, em parte, para o padrão de crescimento mais agressivo exibido por estes cistos.

11. Hume WJ, Moore JK, Main DMG. Diferences in in vitro growth of epithelium from inflammatory and developmental odontogenic cysts. Br J Oral Maxillofac Surg 1990; 28:85-8.

12. Kannan S, Balaram P, Chandran GJ, et al. Alterations in expression of basement membrane proteins during tumour progression in oral mucosa. Histopathology 1994;24:531-7.

13. Lee YJ, Streuli CH. Extracellular matrix selectively modulates the response of mammary epithelial cells to diferent soluble signaling ligands. J Biol Chem 1999;274:22401-8.

14. Liotta LA. Tumor invasion and metastases: role of the basement membrane. Am J Pathol 1984;117:339-48.

15. Meghji S, Qureshi W, Henderson B, et al. The role of endotoxin and cytokines in the pathogenesis of odontogenic cysts. Arch Oral Biol 1996;41:523-31.

16. Scharffetter K, Balz-Herrmann C, Lagrange W, et al. Proliferation kinetics - study of the growth of keratocysts, morpho-functional explanation for recurrences. J Craniomaxillofac Surg 1989;17:226-33.

17. Silva MJA. Cisto odontogênico ortoqueratinizado. Estudo clínico-patológico e imuno-histoquímico. 2000. [Tese de Doutorado], São Paulo: Faculdade de Odontologia de São Paulo da Universidade de São Paulo.

18. Tsubura A, Shikata N, Inui $\mathrm{T}$, et al. Immunohistochemical localization of myoepithelial cells and basement membrane in normal, benign and malignant human breast lesions. Virchows Arch 1998;413:133-9. 